ARTIGO

Recebido em: 28/04/2017

Aceito em: 09/04/2018

\title{
Modelo para avaliação do grau de maturidade das práticas de cocriação de valor no desenvolvimento de produtos
}

\author{
Model for evaluating the maturity degree of value-buying practices in \\ product development
}

\author{
Raniely BLOEMER (ranielybloemer@hotmail.com)* \\ Gérson TONTINI (gersontontini@gmail.com)* \\ * Universidade Regional de Blumenau.
}

\begin{abstract}
Resumo
Com a popularização da Internet e a mudança no perfil do consumidor, em que eles estão mais informados e participativos, as empresas perceberam a oportunidade de interagir de forma próxima com os clientes. Surge então a cocriação de valor. A cocriação de valor possibilita o consumidor participar ativamente na criação de valor com a empresa, resultando em assertividade no lançamento de produtos, melhor entendimento do cliente, maior rapidez no lançamento de produtos, etc. Porém, o uso dessa estratégia ainda não é claro, e este é o objetivo deste trabalho, propor um modelo para mensuração da maturidade em cocriação de valor, com isso, as empresas conseguem identificar o que é necessário para incluir o cliente no processo de inovação, e as melhorias necessárias para atingir um maior nível de maturidade nessa atividade. Para criar o modelo foi realizado estudo bibliográfico e para sua avaliação, foi realizada entrevista em caso único e análise estatística com uma amostra de 13 indústrias. 0 modelo proposto é inédito. Após a entrevista e análise dos dados, concluiu-se que há correlação entre as variáveis do modelo e que parte das variáveis explicam os resultados da cocriação. Ou seja, o modelo de maturidade para cocriação de valor (MMCV) mostrou-se válido, pois apresentou bons resultados, mesmo com a limitação do número da amostra.

Palavras-chave: Cocriação de Valor. Modelo de Maturidade. Desenvolvimento de Produtos.
\end{abstract} Participação do Cliente. Inovação.

\begin{abstract}
With the popularization of the Internet and the change in consumer profile, in which they are more informed and participatory, companies have realized the opportunity to interact closely with customers. The co-creation of value then arises. Value creation allows the consumer to actively participate in value creation with the company, resulting in assertiveness in the launch of products, better understanding of the customer, faster product launches, etc. However, the use of this strategy is still unclear, and this is the purpose of this work, to propose a model for measuring the maturity in value creation, with which companies can identify what is necessary to include the client in the innovation process, and the improvements needed to achieve a higher level of maturity in this activity. In order to create the model, a bibliographic study was carried out and for its evaluation, a single case interview and a statistical analysis were carried out with a sample of 13 industries. The proposed model is unprecedented. After the interview and analysis of the data, it was concluded that there is correlation between the variables of the model and that part of the variables explain the results of the co-creation. That is, the maturity model for value creation (MMCV) was valid, since it presented good results, even with the limitation of the sample number.

Keywords: Co-creation of Value. Maturity Model. Product Development. Customer Participation. Innovation.

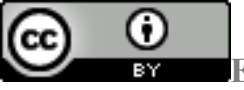
Esta obra está licenciada sob uma Licença Creative Commons.
\end{abstract}

v. 23 , n. esp., 2018 p. $60-75$

ISSN 1518-2924 


\section{INTRODUÇÃo}

O mercado está em constante mudança, observando-se uma evolução no comportamento do consumidor, em decorrência da evolução do mercado. Pode-se dizer que foi o surgimento da Internet que causou as mudanças mais expressivas no mercado e no consumidor, tonando o mercado mais dinâmico e os consumidores mais exigentes, pois as informações de qualquer parte do mundo chegam em cliques (PRAHALAD; RAMASWAMY, 2000; TABORDA, 2007). A popularização das redes sociais on-line facilitou a troca de experiências e conhecimentos de consumidor para consumidor (consumer-to-consumer), tornando-os mais ativos e exigindo transparência das empresas (PRAHALAD; RAMASWAMY, 2000; TABORDA, 2007). Apesar deste cenário ser desafiador, há formas de as empresas incluírem os consumidores como aliados, parceiros e cocriadores de valor (PRAHALAD; RAMASWAMY, 2000; TABORDA, 2007).

A cocriação de valor é a participação e colaboração de clientes, usuários e comunidade, por meio de seu conhecimento, habilidades e experiências, para solucionar um problema comum e criar valor, juntamente com a empresa (PRAHALAD; RAMASWAMY, 2004a, 2004c; PAYNE; STORBACKA; FROW, 2007; VARGO; MAGLIO; AKAKA, 2008; ALLEN BAILETTI; TANEV, 2009; GUSTAFSSON; KRIESTENSSON; WITELL, 2012). Essa colaboração não tem uma forma única de ocorrer. Alguns processos de integração e participação de clientes no desenvolvimento de produtos e criação de valor foram estudados, como o modelo DART de Prahald e Ramaswamy (2004a), o modelo CusI - Customer Involvement Model de Matthing, Sandén e Edvarsson (2004), o modelo CoPP - Co-Production Process Model de Etgar (2008), o modelo SCPS Synectics Creative Problem-Solvin, o modelo COPA - Co-creative Participation Model de Durugbo, Riedel e Pawar (2011), o estudo de Allen, Bailetti e Tanev (2009), e o estudo de Ayunia (2013).

Prahalad e Ramaswamy (2004a) consideram a cocriação de valor como um meio de gerar vantagem competitiva, pois defendem que a interação gera uma experiência exclusiva para cada cliente. Zmoginski et al. (2009) corroboram que a inovação gerada pela cocriação é uma vantagem competitiva, ou seja, a cocriação é um meio e não o fim.

Em um experimento, Matthing, Sandén e Edvardsson (2004) comparam o desenvolvimento de produtos com e sem o envolvimento de clientes, percebendo que a participação do cliente no desenvolvimento de produtos gera redução do tempo de ciclo, a qualidade do serviço é superior, e é uma forma de educar o usuário para o uso do produto. Huertas, Varela e Strehlau (2012) acrescentam que a cocriação é uma ferramenta para diminuir o percentual de erros no lançamento de novos produtos. Já para Dietrich, Brasil e Frio (2013), a cocriação pode não ser considerada um prérequisito de sucesso no mercado, mas é um processo que existe e é viável.

Entretanto, as empresas precisam descobrir a forma correta de interagir com os clientes (PRAHALAD; RAMASWAMY, 2002), para motivá-los a participar, monitorar e gerenciar o caminho ao longo do processo (NGO; O'CASS, 2013). Payne, Storbacka e Frow (2007) afirmam que pouco se sabe sobre como os clientes se envolvem na cocriação de valor, e como identificar quais são as oportunidades de cocriação mais vantajosas (FROW et al., 2015). De acordo com Gustafsson, Kriestensson e Witell (2012), esse comportamento ocorre pelo fato do valor ser tácito, dificultando a identificação, compreensão e adoção de processos de criação de valor com o cliente. Com isso, surge a ideia de criar um modelo de maturidade para cocriação de valor, pois modelo de maturidade é um conjunto de artefatos que auxiliam pessoas, organizações, áreas e processos a crescer e evoluir em direção a uma maturidade mais elevada, sendo considerado ainda, o caminho para o sucesso da empresa, pois mostra o que corrigir e a prevenir problemas que impedem a melhoria dos processos (BECKER; KNACKSTEDT; 
POPPELBUB, 2009; ROCHA; VASCONCELOS, 2004; SILVEIRA; GUIMARÃES; ABRAÃO, 2007).

Diante do exposto, essa pesquisa visa iniciar uma discussão sobre modelos de maturidade para cocriação de valor, pois nenhum estudo foi encontrado sugerindo um instrumento para mensurar a maturidade desta variável, acrescido a importância, já descrita anteriormente, da participação do cliente no desenvolvimento de produtos para a competitividade da empresa. Assim, esta pesquisa tem como objetivo: propor um modelo de maturidade para medir a cocriação de valor no desenvolvimento de produtos.

\section{PROPOSTA DE UM MODELO DE MATURIDADE PARA COCRIAÇÃO DE VALOR - MMCV}

Com base na pesquisa das 15 dimensões de cocriação de valor de Ayunia (2013), o modelo DART de Prahalad e Ramaswamy (2004) e o CMMI® (Capability Maturity Model $®$ Integration), o presente modelo de maturidade foi desenvolvido. Este modelo foi projetado para o desenvolvimento de produtos em parceria da empresa com o cliente final, portanto, seu uso é indicado para esse cenário.

Considerando as etapas de cocriação de valor como: iniciação da cocriação; envolvimento com o cliente; processo de inovação; e resultado da cocriação; as dimensões consideradas neste modelo foram: a) iniciador, b) motivação, c) propósito, d) nível de intimidade, e) local de interação, f) tamanho do grupo de cocriação, g) estímulos, h) tipos de cocriadores, i) uso de mediador, j) plataforma de colaboração, k) duração, l) sistema de suporte interno da empresa, m) governança, e n) valor da cocriação. Passaremos a seguir, discutir essas dimensões.

\subsection{Dimensões do MMCV}

\subsubsection{Dimensão: Iniciador}

Iniciador refere-se a quem toma a iniciativa da atividade de cocriação, que podem ser tanto a empresa, como o cliente, apesar do segundo caso ser considerado mais raro (AYUNIA, 2013). Essa dimensão mede a intenção e os recursos que a empresa disponibiliza que permitem incluir o cliente na fase inicial da cocriação.

\subsubsection{Dimensão: Motivação (perspectiva do cliente)}

Motivação é a razão que leva o cliente a participar da atividade de cocriação, essa razão pode ser intrínseca ou extrínseca (AYUNIA, 2003). Motivação intrínseca refere-se aos fatores psicológicos que inclui o desejo e a autodeterminação, já a motivação extrínseca refere-se a uma recompensa externa como monetária direta ou indiretamente e até reconhecimento (RAFAELI; ARIEL, 2008). Vale destacar que a participação motivada por razões intrínsecas torna atividade de cocriação mais intensa (AYUNIA, 2003). Entretanto, essa afirmação é positiva somente se nunca foi fornecida uma motivação extrínseca, pois o estímulo externo pode diminuir a motivação intrínseca do participante (RAFAELI; ARIEL, 2008). Com isso, nessa dimensão mede-se o tipo de motivação que a empresa percebe que o cliente precisa para participar das atividades de cocriação.

\subsubsection{Dimensão: Propósito (perspectiva da empresa)}

Propósito da perspectiva da empresa são os motivos que levaram a organização incluir a cocriação no processo de desenvolvimento de produtos. 0 propósito pode ser 
apenas um ou pode ser mais de um e ocorrer sobreposição entre eles. Os propósitos são quatro: resolução de problemas, co-inovação, validação e melhoria, pesquisa e desenvolvimento, compra e buzz (AYUNIA, 2013). A participação de membros externos à empresa é como uma equipe multidisciplinar em uma proporção aumentada, ou seja, vários indivíduos com formações e vivências diferentes, pensam melhor do que apenas um indivíduo ou uma equipe interna da empresa. Com a popularização da Internet e a possibilidade de interação da Web 2.0 facilitou a participação de consumidores em todos os processos internos que a empresa deseja compartilhar (BRABHAM, 2008). Nessa dimensão mede-se o(s) motivo(s) pelo(s) qual(is) a empresa decidiu incluir os clientes como cocriadores de valor no desenvolvimento de produtos.

\subsubsection{Dimensão: Nível de intimidade}

Nível de intimidade é o nível de envolvimento entre a empresa e o cliente, que foram classificados como leve, moderado ou intensivo, porém há outras duas variáveis que influenciam no nível de intimidade, são estes o local de interação e a plataforma de colaboração. 0 local de interação são as etapas no processo de inovação que o cliente pode participar, e a plataforma de colaboração são as formas como o cliente pode participar, presencialmente, virtualmente ou de ambas as formas (AYUNIA, 2013). Com isso, entende-se que quanto mais locais de interação o cliente participar, maior será sua intimidade com a empresa, e da mesma forma com a plataforma de colaboração, se o

cliente participar mais de forma presencial, maior será o nível de intimidade com a empresa. Com isso, essa dimensão tem o objetivo de medir proximidade entre cliente e empresa.

\subsubsection{Dimensão: Local da interação}

O local de interação é a etapa da inovação que ocorrerá a atividade de cocriação de valor. Neste caso foram consideradas seis etapas para o processo de inovação, são elas: planejamento estratégico, desenvolvimento e triagem de ideias, analise de negócios e oportunidades de mercado, desenvolvimento técnico, teste de validação e pós-lançamento (AYUNIA, 2013).

0 processo de planejamento estratégico fornece direção ao processo, estabelecendo os objetivos financeiros e de marketing, ainda orienta a seleção de campo para investigar novas ideias de produtos. Duas funções do processo de planejamento estratégico são ressaltadas: a determinação da necessidade de inovação (avaliação da situação) e a determinação de áreas de pesquisa, estas duas etapas fornecer orientação para geração de ideias, cobrança e rastreio. A necessidade de inovação é determinada pela analise da situação/mercado, muitas vezes por meio de pesquisa de mercado; e avaliação do ambiente competitivo, das forças e fraquezas, que ajudam a determinar o foco da inovação. Definido o foco as próximas etapas são a geração e a triagem de ideias, a geração de ideias é o processo criativo para identificar ideias de possíveis novos produtos, em seguida as ideias são avaliadas para que os recursos da empresa sejam todos dedicados à ideia mais viável (ROCHFORD, 1991). Na sequência vem a etapa de desenvolvimento técnico, é o momento do desenvolvimento do produto em si e ao mesmo tempo, testes detalhados de marketing, planos de operação, revisão financeira, reparos e questões legais, como registro de patente e certificações. A etapa de validação testa toda a viabilidade do projeto: o produto em si, o processo de produção, aceitação do cliente e o financeiro do projeto; diversas atividades são elaboradas nesta fase, desde testes de protótipo in company, teste de campo com o cliente, teste piloto, teste experimental de produção e até teste de comercialização. Para finalizar o projeto e o produto tornar-se um "produto regular", há a etapa de pós-lançamento, onde o 
desempenho do projeto é revisado, é realizado levantamento de receitas, custos, despesas, lucro e tempo, e comparado com a projeção inicial para avaliar o desempenho do produto, acontece uma análise crítica observando os pontos fortes e fracos do projeto para observar o que pode ser aprendido com este projeto e como poderia ter sido feito melhor (COOPER, 1990).

Nesta dimensão mede-se quanto o cliente participa das atividades de cocriação de valor, em cada uma das seis etapas consideradas no processo de inovação.

\subsubsection{Dimensão: Tamanho do grupo de cocriação}

Tamanho do grupo de cocriadores refere-se ao número de participantes nas atividades de cocriação da empresa, que podem ser grupos pequenos, médios ou grandes. Essa dimensão relaciona-se com as dimensões nível de intimidade e plataforma de colaboração. Quanto maior o número de cocriadores, menor o nível de intimidade (AYUNIA, 2013). Diante disso, essa dimensão mede o tamanho do grupo de cocriadores e a relação que o tamanho do grupo exerce no nível de envolvimento entre cliente e empresa, e cliente com outros clientes.

\subsubsection{Dimensão: Estímulos (nível-empresa)}

Estímulos são esforços feitos pela empresa para estimular a participação de cocriadores externos à empresa. Foram encontrados duas formas, a diminuição de custos e o aumento de benefícios para os clientes participantes de cocriação, para maior eficiência das atividades de cocriação, deve haver um ajuste entre a motivação e o estímulo dado pela empresa (AYUNIA, 2013). Nesta dimensão mede-se os estímulos que a empresa proporciona para atrair os clientes para atividades de cocriação.

\subsubsection{Dimensão: Tipos de cocriadores}

Tipos de cocriadores refere-se à categorização dos cocriadores em relação as suas competências, experiências e perfil, outra forma de escolher o participante é pela finalidade da atividade. Uma observação deve ser feita aqui, ao falar de cliente não se refere apenas ao público que compra, mas de uma forma abrangente, ou seja, do cliente que compra e do potencial cliente da empresa. Foram definidas três categorias explicadas pela habilidade do cliente, perfil do cliente e usuários de peso (AYUNIA, 2013). Nessa dimensão a intenção é avaliar o critério de escolha que a empresa utiliza para montar o grupo de cocriadores.

\subsubsection{Dimensão: Uso de mediador}

Uso de mediador explica se a empresa utiliza o serviço de um intermediário à inovação ou uma empresa de consultoria. 0 mediador é a pessoa responsável por realizar as atividades de cocriação, que pode ser desde projetar a plataforma de cocriação até selecionar os cocriadores. As empresas percebem o uso de mediador como uma atividade necessária para proteger o projeto, o produto, a empresa e a marca (AYUNIA, 2013). Essa dimensão mede se as atividades de cocriação são organizadas e melhor aproveitadas com o auxilio do serviço de um mediador.

\subsubsection{Dimensão: Plataforma de Colaboração}

Plataforma de cocriação pode ser definida como físico ou virtual. A plataforma física são os encontros presenciais em um espaço físico, que podem ser workshop e reuniões. A plataforma virtual ou online são locais de interação virtual, como website da empresa, site de cocriação e redes sociais. Pode ocorrer de a empresa optar por utilizar as duas formas de interação, em uma etapa do processo de cocriação a interação virtual 
e em outra etapa a forma virtual, a escolha vai depender dos objetivos da empresa (AYUNIA, 2013). Nesta dimensão avalia-se o local aonde são realizados os encontros para cocriar.

\subsubsection{Dimensão: Duração (perspectiva da empresa)}

Neste trabalho duração possui relação com as etapas de inovação, ou seja, a atividade de cocriação pode acontecer em uma fase do processo de inovação, em múltiplas fases ou de um modo contínuo, passando por todo o processo de inovação (AYUNIA, 2013). De acordo com Fuller e Matzler (2007) as formas de interação com o cliente pode ocorrer em uma tarefa específica do processo ou contínua durante o desenvolvimento completo de um projeto ou de vários projetos. Com isso, essa dimensão mede a forma como os participantes atuam nas atividades de cocriação de valor, com base nas fases do processo de inovação.

\subsubsection{Dimensão: Sistema de suporte interno da empresa}

Sistema de suporte interno da empresa refere-se ao sistema da empresa que suporta a cocriação, por meio do processamento de informações recolhidas a partir da participação dos clientes no processo de inovação. Considerando a robustez do sistema, foram elencadas duas categorias, ad hoc e sistemática (AYUNIA, 2013).

Os sistemas ad hoc caracterizam-se por serem mais básicos, “é capaz de descrever processos simples, nos quais não há padrão fixo para o fluxo de informações entre as pessoas envolvidas", entretanto, é o mais utilizado e é uma preparação para receber um sistema mais elaborado (LAMPERT; FLORES, 2010, p. 220). Já os modelos sistemáticos são mais elaborados, diferenciam-se por terem etapas definidas para serem seguidas e por revisar a qualidade com frequência (TSUKUMO et al., 1997).

Essa dimensão avalia as características do sistema interno da empresa, utilizado para processar as informações geradas nas atividades de cocriação de valor.

\subsubsection{Dimensão: Governança}

Governança são as regras formais e informais que regem a relação clienteempresa em todo o processo de interação entre os envolvidos. Neste caso, foi utilizada uma forma genérica que envolve governança hierárquica, governança de mercado e governança relacional (AYUNIA, 2013). Governança relacional vai além de contratos formais, o cumprimento das obrigações ocorre por meio de processos sociais que permite flexibilidade, solidariedade e troca de informações. A flexibilidade facilita a adaptação a imprevistos; a solidariedade promove uma abordagem bilateral para resolução de problemas, criando um compromisso mutuo; e a troca de informações facilita a resolução de problemas e adaptações, pois todos estão dispostos a compartilhar informações privadas (POPPO; ZENGER, 2002). Governança hierárquica é uma forma de proteger com maior afinco as partes, são "regras e procedimento para controle de atividades, [...] pode assumir a forma de dar a um dos atores o direito de decidir e controlar questões específicas ou para implementar procedimentos operacionais padrão" (HAUGLAND, 1999, p. 274). E por fim, governança de mercado que consiste em passar a responsabilidade de gestão do setor público para o setor privado, com o objetivo de maior eficiência (VAN HOI; MOL; OOSTERVEER, 2009).

Essa dimensão mede a forma como se estabelece as regras de convivência durante as atividades de cocriação de valor. 


\subsubsection{Dimensão: Valor da Cocriação}

O valor da cocriação considera os valores criados a partir da cocrição, porém não se limita apenas ao valor criado no momento da interação, mas o valor criado ao longo de todo o processo de cocriação. Nesta dimensão há uma ressalva, que o valor não deve ser definido por tipo de valor e sim por experiência, desta forma os valores cocriados consistem em valor cocriado para o cliente e valor cocriado para a empresa (AYUNIA, 2013).

A definição de valor não tem um consenso, por ser interpretado em diversos usos, possui diversos significados, em uma visão ampla e genérica valor é a diferença entre os benefícios e os sacrifícios percebidos ao adquirir algum bem ou serviço (WOODRUFF, 1997; FERNÁNDEZ; BONILLO, 2007).

A dimensão valor da cocriação foi dividida em duas, por se tratar da visão de valor de dois atores sociais que ficam em lados diferentes do processo de cocriação de valor. 0 valor da cocriação para o cliente mede, na visão da empresa, os benefícios que levam o cliente a cocriar. Já o valor da cocriação para a empresa, mede as vantagens que a empresa percebe para si ao exercer atividades de cocriação de valor com o cliente.

\subsection{Avaliando o nível de maturidade de cada dimensão}

A avaliação de maturidade de cada dimensão é efetuada mensurando-se o nível que se encontra a empresa, conforme exemplo do Quadro 1.

Quadro 1: Motivação - refere-se a razão que leva o cliente a participar da atividade de cocriação

\begin{tabular}{|c|l|}
\hline $\begin{array}{c}\text { Nível } \\
\mathbf{1}\end{array}$ & $\begin{array}{l}\text { A empresa não propicia motivação aos clientes, sendo que estes não têm motivação } \\
\text { para participar em atividades de cocriação. }\end{array}$ \\
\hline $\begin{array}{c}\text { Nível } \\
\mathbf{2}\end{array}$ & $\begin{array}{l}\text { Os clientes têm alguma motivação para participar na cocriação, porém apenas se } \\
\text { recebendo benefícios explícitos (brinde, pagamento, etc.). }\end{array}$ \\
\hline $\begin{array}{c}\text { Nível } \\
\mathbf{3}\end{array}$ & $\begin{array}{l}\text { Os clientes têm forte motivação para participar na cocriação, mas recebendo benefícios } \\
\text { explícitos (brinde, pagamento, etc.). }\end{array}$ \\
\hline $\begin{array}{c}\text { Nível } \\
\mathbf{4}\end{array}$ & $\begin{array}{l}\text { A empresa efetua integração com seus clientes, sendo que estes participam } \\
\text { espontaneamente nas atividades de cocriação, já sem necessidade de estímulos } \\
\text { externos. Porém não mantem regularidade na participação. }\end{array}$ \\
\hline $\begin{array}{c}\text { Nível } \\
\mathbf{5}\end{array}$ & $\begin{array}{l}\text { A empresa efetua integração com seus clientes, sendo que estes participam } \\
\text { espontaneamente, e regularmente nas atividades de cocriação, já sem necessidade de } \\
\text { estímulos externos para sua participação. }\end{array}$ \\
\hline
\end{tabular}

Fonte: Elaborado pela autora (2016).

Para cada dimensão desenvolveu-se os diferentes níveis de maturidade, sendo que a maturidade final, em termos de cocriação, é calculada pela é calculada pela soma da pontuação dada dentro da escala de 1 a 5 . Se o resultado dessa soma for de 70 pontos a empresa classifica-se como nível 5; se a soma for entre 69 e 56 pontos, a empresa classifica-se como nível 4; se a pontuação for entre 55 e 42 pontos, a empresa classifica-se como nível 3, pontuação entre 41 e 28, a empresa classifica-se como nível 2; se for entre 27 a 14 pontos, a empresa classifica-se como nível 1; e abaixo do nível 1 se tiver menos que 14 pontos. . A descrição dos diferentes níveis de maturidade de cada fator analisado encontra-se em anexo deste artigo.

\subsection{Níveis de maturidade do MMCV}

Para criar os níveis de maturidade do Modelo de Maturidade de Cocriação de Valor foi considerado o CMMI®, pois seu objetivo é auxiliar na organização e melhoria de processos no desenvolvimento e manutenção de produtos e serviços, e o Modelo 
DART, que segundo Prahalad e Ramaswamy (2004a) consideram a base para a cocriação de valor e a forma de iniciar um sistema de cocriação de valor entre consumidor e empresa para facilitam a cocriação de experiência, desta união resultou os cinco níveis do Quadro 2.

Quadro 2: Níveis de maturidade MMCV

\begin{tabular}{|c|c|c|}
\hline $\begin{array}{c}\text { Níve } \\
\text { l }\end{array}$ & $\begin{array}{c}\text { Nível de } \\
\text { maturidade }\end{array}$ & Explicação \\
\hline 1 & Inicial & $\begin{array}{l}\text { As empresas de maturidade } 1 \text { possuem processos de cocriação pouco } \\
\text { estruturado e com poucos recursos, entretanto possuem atividades de } \\
\text { cocriação que funcionam, apesar de não conseguirem absorver e armazenar } \\
\text { todas as ideias geradas. Outra tendência das empresas neste nível é atividade } \\
\text { de cocriação acontecer apenas em uma fase do processo de inovação e com } \\
\text { pouco diálogo de troca de informações. }\end{array}$ \\
\hline 2 & Gerenciado & $\begin{array}{l}\text { Empresas com nível de maturidade } 2 \text { possuem projetos com processos de } \\
\text { cocriação e executados conforme planejado, com acompanhamento de pessoa } \\
\text { não exclusiva, mas garantindo a permanência dos processos em momentos de } \\
\text { crise, porém não conseguindo armazenar todas as ideias geradas. As fases dos } \\
\text { projetos são determinadas e visíveis, e a cocriação ocorre em etapas } \\
\text { específicas, há uma pequena troca de informaçõos entre todos os envolvidos. }\end{array}$ \\
\hline 3 & Definido & $\begin{array}{l}\text { As empresas com nível de maturidade } 3 \text { possuem plataforma de cocriação } \\
\text { exclusiva para a atividade, com uma pessoa exclusiva para o } \\
\text { acompanhamento, garantindo o armazenamento de todas as ideias, um } \\
\text { diálogo de troca e com bom perfil de participantes. Os processos são } \\
\text { gerenciados mais "proativamente". }\end{array}$ \\
\hline 4 & $\begin{array}{c}\text { Gerenciado } \\
\text { quantitativament } \\
\text { e }\end{array}$ & $\begin{array}{l}\text { Empresas com nível de maturidade } 4 \text { possuem objetivos de cocriação claros, a } \\
\text { atividade de cocriação é continua e bem estruturada. Possui participação ativa } \\
\text { dos clientes, que participam pelo sentimento de fazer o bem. Conseguem } \\
\text { monitorar todo o envolvimento e as ideias geradas, além do comportamento e } \\
\text { identificar o que o cliente considera como de valor para ele, mesmo de forma } \\
\text { virtual. }\end{array}$ \\
\hline 5 & Em otimização & $\begin{array}{l}\text { Empresas com nível de maturidade } 5 \text { possuem foco na melhoria contínua do } \\
\text { desempenho de processo por meio de melhorias incrementais e inovadoras de } \\
\text { processo e de tecnologia. As atividades de cocriação ocorrem em todas as } \\
\text { fases do processo de inovação, o nível de intimidade com os participantes é } \\
\text { alto, pois o diálogo de troca é intenso e são usadas plataformas de interação } \\
\text { tanto virtual como física. As ideias armazenadas são revistas pensando em } \\
\text { criar novos mercados. }\end{array}$ \\
\hline
\end{tabular}

Fonte: Elaborado pela autora (2016).

\section{METODOLOGIA}

Para atender o objetivo de criar um modelo para medir a maturidade em cocriação de valor, optou-se por um estudo misto. Inicialmente de abordagem qualitativa, classificado como investigação exploratória e de natureza básica, utilizou-se pesquisa bibliográfica, estudo de caso e entrevista.

A pesquisa exploratória para Cervo e Bervian (2002) é o passo inicial no processo de pesquisa. Consiste em definir objetivos e buscar mais informações sobre determinado assunto, com intuito de familiarizar-se com o tema e descobrir novas ideias. Com isso, a presente pesquisa iniciou com um levantamento bibliográfico para verificar a existência de modelos de maturidade de cocriação de valor, porém nenhum modelo foi encontrado, em seguida, outra busca nas bases de dados sobre cocriação de 
valor foi realizada, por meio deste termo alguns estudos foram encontrados, conforme apresentado no referencial teórico deste trabalho. Como cocriação de valor é um termo relativamente novo no meio acadêmico e por não ter um conceito fortemente aceito, optou-se por pesquisar desenvolvimento de produtos com a participação do cliente para verificar outras ferramentas de interação com o cliente e diferenciar as pesquisas de mercado convencionais das novas formas de incluir o consumidor no desenvolvimento de produtos, enfatizando o objetivo da pesquisa bibliográfica que é conhecer e analisar as contribuições passadas de determinado assunto (CERVO; BERVIAN, 2002).

A partir das dimensões e indicadores de Ayunia (2013) foram desenvolvidas, com base na literatura, as práticas do novo modelo para cada um dos indicadores encontrados, juntamente com o CMMI ${ }^{\circledR}$ (Capability Maturity Model ${ }^{\circledR}$ Integration) ajustado com indicações do Modelo DART de Prahalad e Ramawamy (2004a), a proposta do Modelo de Maturidade de Cocriação de Valor - MMCV foi concluído.

Com a intensão de verificar se o modelo proposto cabe à realidade da indústria brasileira, o Modelo de Maturidade de Cocriação de Valor foi aplicado e discutido em uma empresa, sob avaliação da proprietária, por meio de entrevista. De acordo com Cervo e Bervian (2002, p. 46), entrevista "não é uma simples conversa. É uma conversa orientada para um objetivo definido: recolher, por meio do interrogatório do informante, dados para a pesquisa". Nesta ocasião, cada uma das questões do modelo foram discutidas. A entrevista foi realizada pessoalmente em Curitiba, no escritório da empresa pesquisada, em julho de 2016. Toda a conversa foi grava e posteriormente transcrita, para facilitar a análise das informações.

Para a validação do instrumento, uma pesquisa de abordagem quantitativa foi necessária, pois esse tipo de análise, que utiliza de dados e análises estatísticas, garante a precisão dos resultados, sem a influência da interpretação do pesquisador (RICHARDSON, 1999). Criou-se um questionário no Google Drive e este foi enviado por e-mail para uma amostra escolhida por conveniência de 80 empresas, no mês de setembro de 2016. O critério de escolha dessas empresas primeiramente que fosse indústrias e que o negócio fosse B2C, ou seja, que os produtos fossem destinados ao cliente final. Destas 80 empresas, 14 responderam, porém, um dos questionários teve que ser excluído. Em conversa com o respondente, o mesmo relatou ter respondido o questionário pensando no comércio e não na indústria. Com isso, a amostra finalizou com 13 questionários válidos.

As análises estatísticas foram concebidas no software estatístico SPSS versão 21. Primeiramente realizou-se uma análise fatorial exploratória. Segundo Hair et al. (2005, p. 91) "análise fatorial aborda o problema de analisar a estrutura das inter-relações (correlação) entre um grande número de variáveis, definindo um conjunto de dimensões latentes comum". Essa diminuição das variáveis facilita a interpretação dos dados. Assim como a rotação varimax, também utilizada na análise. A rotação varimax tende a intensificar a carga do fator para próximo de 1 ou -1 e a 0 , demonstrando uma clara associação, ou a falta dela, entre as variáveis (HAIR et al., 2005). Posteriormente a matriz de correlação foi concebida, confirmando a correlação existente entre as novas variáveis. Esse tipo de análise "consiste em identificar as variáveis específicas que pareçam ser importantes para explicar complexas características de um problema ou comportamento" (RICHARDSON, 1999, p. 71). Apesar da correlação mostrar a relação entre as variáveis, ela não explica a análise de causa-efeito. Para isso, duas regressões foram geradas. A análise de regressão tem o objetivo de buscar o valor desconhecido de uma variável (variável dependente), por meio dos valores conhecidos de outras 
variáveis (variáveis independentes) (HAIR et al., 2005). Neste caso, utilizou-se como variável dependente Desempenho da Cocriação e Motivadores.

\section{RESULTADO DA PESQUISA}

O questionário foi aplicado em 13 indústrias que tinham como destino do seu produto o cliente final.

Devido à dificuldade de mesurar a cocriação de valor e seu desempenho, optouse por utilizar análise fatorial exploratória. Inicialmente, foi feita a rotação entre as variáveis analisadas, por meio da análise de componentes e rotação varimax. Essa rotação intensifica a carga da variável no grupo em que ela mais se correlaciona (HAIR et al., 2005).

Neste processo as variáveis agruparam-se em 6 fatores, denominados: Motivadores; Cocriação Des. Produtos; Governança; Valor Cocriação; Mediador; e Cocriação Mercado. Todos os novos fatores apresentaram Alfa de Cronbach igual ou acima de 0,60, ou seja, a confiabilidade das respostas é boa, considerando o baixo número de respondentes, segundo a literatura (HAIR et al., 2005).

Dos seis fatores gerados, o primeiro representa $63,74 \%$ do modelo, e quatro deles representam 100\%, com Alfa de Cronbach de 0,78, ou seja, essas quatro variáveis possuem confiabilidade, ou são consistentes para medir o desempenho da cocriação de valor. Quanto ao fator resultados, quatro das cinco variáveis, tornaram-se um fator, o fator Desempenho Cocriação. São eles: estar à frente dos concorrentes em relação ao atendimento das necessidades dos clientes, lançamento de produtos adequados às necessidades dos clientes, estar à frente dos concorrentes em relação ao tempo de lançamento, e sucesso de produtos lançados. Apenas a variável produtos cocriados possuem percentual de vendas maior que os não cocriados, não agrupou-se ao fator Desempenho Cocriação.

Em seguida, para avaliar se há relação entre as variáveis pesquisadas para cocriação e seus resultados, foi gerada a matriz de correlação com a média dos construtos.

De acordo com Hair et al. (2005) a matriz de correlação mostra a intercorrelação entre todas as variáveis, e é isso que comprova a validade do modelo, pois existe uma conversa, ou uma ligação entre as variáveis, apesar de não se saber o tipo de relação entre elas. As variáveis que apresentaram alta correlação com significância igual ou menos que 0,05 foram: Des. Cocriação, Motivadores, Cocriação Mercado, Mediador, Valor Cocriação, e Governança. Uma das variáveis, mesmo com significância fora dos padrões segundo a literatura, foi destacada, pois considerou-se o baixo número da amostra. Esta foi o Mediador com Sig .de 0,093.

Seguindo com a análise estatística, foi realizada duas regressões linear, para entender a relação entre as variáveis. A primeira regressão foi com a variável Desempenho da Cocriação como variável dependente, e a segunda com a variável dependente Motivadores, que culminou na Figura 1. 


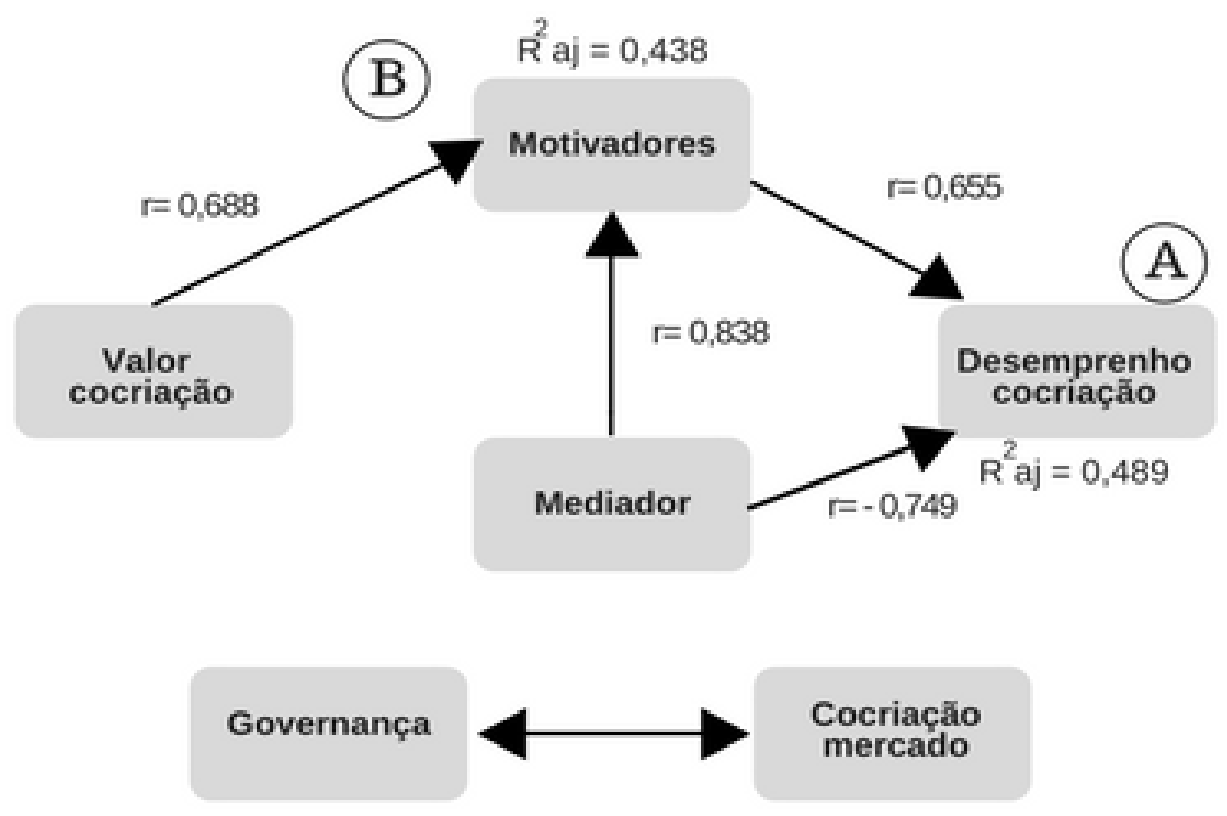

Figura 1: Modelo da pesquisa

Fonte: Elaborado pela autora (2016).

Observando a parte A da figura, apresenta-se uma correlação negativa entre o desempenho da cocriação e o mediador, ou seja, quanto mais há a presenta e interferência de um mediador nas atividades de cocriação, menor é o desempenho da cocriação de valor. Esse comportamento é explicado por $r$ negativo. Sendo a correlação entre as variáveis de 0,749 e o grau de explicação é de $56 \%$.

Já a variável mediadora tem uma correlação positiva de 0,838 com a variável motivadores e variância compartilhada de 0,702. E a variável motivadores uma correlação positiva de 0,655 e variância compartilhada de 0,429 com a variável desempenho da cocriação. Ou seja, a presença de um mediador incentiva e instiga os motivadores que apresentam um resultado positivo no desempenho da cocriação. Que são: estar à frente dos concorrentes em relação ao atendimento das necessidades dos clientes, lançamento de produtos adequados às necessidades dos clientes, estar à frente dos concorrentes em relação ao tempo de lançamento, e sucesso de produtos lançados. Essa parte do modelo apresenta $\mathrm{R}^{2}$ ajustado de 0,489 . Essa informação representa que $48,90 \%$ da variável dependente é explicada pelas variáveis independentes presentes no modelo.

Na parte B da figura, demonstra que a variável valor da cocriação possui uma correlação positiva de 0,688, o que corresponde á variância compartilhada de 0,473, com a variável motivadores. Isso significa que quanto maior se percebe valor na cocriação, maior são os motivadores e motivações para a cocriação de valor, explicada pelo grau de variância de 47,3\%. Essa parte do modelo apresenta $\mathrm{R}^{2}$ ajustado de 0,438 , ou seja, $43,80 \%$ da variável dependente é explicada pela variável independente.

Por outro lado, na parte inferior da figura, observa-se que Governança e Cocriação Mercado não apresentam conexão com o modelo, apenas relacionam-se entre si, e mesmo assim, não foi possível identificar qual o tipo de relação há entre elas.

0 modelo utilizou método stepwise com $p$-value de 0,10 , ou seja, a probabilidade do ocorrido ter sido ao acaso é baixa. 


\section{CONSIDERAÇÕES PARCIAIS}

Essa pesquisa teve como objetivo propor um modelo para mensuração da maturidade em cocriação de valor. $\mathrm{Na}$ pesquisa bibliográfica sobre o tema, foi encontrado o estudo de Ayunia (2013), que tornou-se base para o modelo de maturidade proposto, juntamente com o modelo DART de Prahalad e Ramaswamy (2004a) e o CMMI.

Para verificar a aplicabilidade do instrumento para medição da maturidade em cocriação de valor no desenvolvimento de produtos, foi realizado primeiramente por uma entrevista. 0 modelo foi aplicado e discutido com uma empresa que utiliza a cocriação de valor em seus projetos. Apesar da empresa pesquisada limitar a cocriação a uma ferramenta de geração de ideias e não ater-se ao mercado, foi possível avaliar o modelo. Todas as questões se mostraram apropriadas ao modelo de maturidade, mesmo que em alguns casos houveram respostas contrárias da entrevistada, por consequência de algumas limitações de conhecimento e ferramentas.

Em um segundo momento o modelo foi aplicado em 13 indústrias e gerado testes estatísticos para validação do mesmo. O baixo número de respondentes influenciou na análise, entretanto, mesmo com essa limitação, observou-se que o modelo já dá indícios de atender o objetivo de mensurar a maturidade em cocriação de valor.

0 primeiro teste realizado foi a análise fatorial exploratória que uniu as 20 variáveis em 6 fatores, e todos os fatores apresentaram Alfa de Crombach acima de 0,60. $\mathrm{Ou}$ seja, todos os fatores demonstram consistência para mediar suas variáveis correspondentes. Da mesma forma ocorreu com os resultados da cocriação, quatro das variáveis uniram-se gerando o fator Desempenho Cocriação, com Alfa de Crombach de 0,78 . Apenas a variável produtos cocriados possuem percentual de vendas maior que os não cocriados, não agrupou-se ao novo fator.

Em seguida foi analisada a correlação entre as variáveis do modelo. É essa análise que comprova se o modelo é consistente ou não. Algumas variáveis apresentaram correlação com significância igual ou abaixo de 0,05 . Por outro lado, outras não apresentaram correlação com significância. Para entender melhor o modelo, duas regressões foram geradas, uma com Desempenho Cocriação como variável dependente, e outra com a variável Motivadores como dependente.

0 resultado foi que quanto mais há a presenta e interferência de um mediador nas atividades de cocriação, menor é o desempenho da cocriação de valor. Por outro lado, se o mediador incentivar os participantes da atividade de cocriação, estas demonstram resultados positivos para o desempenho da cocriação. Assim como o valor da cocriação. Se os participantes das atividades de cocriação perceberem maior valor nas atividades, maior será sua motivação ao participar, e por consequência, maior o desempenho da cocriação.

Por outro lado, observou-se que Governança e Cocriação Mercado não apresentam conexão com o modelo, apenas relacionam-se entre si, porém, não foi possível identificar qual o tipo de relação existe entre elas.

0 modelo apesentou $p$-value de 0,10 , que significa que a probabilidade dos resultados serem mero acaso é baixa.

Como contribuição gerencial o trabalho apresenta ferramentas e processos para incluir o cliente no desenvolvimento de produtos, não apenas de forma passiva como ocorre nas ferramentas tradicionais, mas principalmente alertando para as ferramentas atuais, em que os clientes participam ativamente no desenvolvimento de produtos e cocriação de valor, demonstrando suas preferências, desejos e necessidades. Além disso, 
o trabalho entrega um instrumento para medir a maturidade dessa interação, das atividades de cocriação de valor. Esse instrumento permite à empresa auto aplicar, se auto avaliar e ainda monstra o caminho a percorrer para sua evolução em busca de uma maturidade mais elevada.

Quanto à contribuição acadêmica, essa pesquisa incrementa a discussão sobre cocriação de valor, que ainda não está saturada, principalmente em campo nacional, e ela sugere um modelo de maturidade para cocriação de valor inédito até o momento.

Um dos fatores limitantes deste estudo é o número da amostra. 0 baixo número de respondentes da pesquisa limitou as análises estatísticas, e os resultados das análises realizadas, foram com números abaixo do considerado ideal, em alguns casos. Como base no exposto, as sugestões para futuros estudos são: avaliar o modelo proposto da perspectiva de outras empresas, principalmente empresas que já demonstrem um bom nível de maturidade, e que o modelo seja aplicado em um número maior de empresas para que análises estatísticas consistentes sejam realizadas.

\section{REFERÊNCIAS}

ALLEN, Stephen; BAILETTI, Tony; TANEV, Stoyan. Components of co-creation. Open Source Business Resource. 2009.

AYUNIA, Shinta. Measuring the unmeasured: na exploratory study of customer co-creation. 2013. 127 f. Dissertação (Management of Technology) - Delft University of Technology, Delft, Holanda. 2013.

BECKER, Jorg; KNACKSTEDT, Ralf; POPPELBUB, Jens. Developing maturity models for IT management. Business \& Information Systems Engineering, Alemanha, v. 1, n. 3, p. 213-222, jun. 2009.

CERVO, Amado L.; BERVIAN, Pedro A. Metodologia Científica. São Paulo, Prentice Hall, 2002.

COOPER, Robert G. Stage-gate systems: a new tool for managing new products. Business Horizons, v. 33, n. 3, p.44-54, jun. 1990.

DIETRICH, Jorge Fernando; BRASIL, Vinícius Sittoni; FRIO, Ricardo Saraiva. 0 processo de cocriação de valor entre empresas e consumidores: uma análise comparativa de dois casos da indústria de bens de consumo. Revista de Administração IMED, v. 3, n. 3, p. 221-238, 2013.

DURUGBO, Christopher; RIEDEL, Johann; PAWAR, Kulwant. Towards a unified model of cocreation. In: INTERNATIONAL CONFERENCE ON CONCURRENT ENTERPRISING, 17., 2011, Aachen. Anais eletrônicos ... Aachen, 2011.

ETGAR, Michael. A descriptive modelo $f$ the consumer co-production process. Journal of the Academy of Marketing Science, v. 36, n. 1, p. 97-108, mar. 2008.

FENG, Taiwen; WANG, Dan. Supply chain involvement for better product development performance. Industrial Management \& Data Sustems, v. 113, n. 2, p. 190-206, 2013.

FERNÁNDEZ, Raquel Sánchez; BONILLO, M. Ángeles Iniesta. The concepto f perceived value: a systematic review of the research. Marketing Theory, v. 7, n. 4, p. 427-451, dez. 2007.

FILIERI, Raffaele. Consumer co-creation and new product development: a case study in the food industry. Marketing Intelligence \& Planning, v. 31, n. 1, p. 40-53, 2013. 
FINCH, Byron J. Internet discussions as a source for consumer product customer involvement and quality information: na exploratory study. Journal of Operations Mnagement, v. 17, n. 5, p. 535-556, ago. 1999.

FRIO, Ricardo Saraiva. Comportamento de cocriação de valor do consumidor: moderação e consequências. 2014. 121 f. Dissertação (Administração e Negócios) - Pontifícia Universidade Católica do Rio Grande do Sul, Porto Alegre, Brasil. 2014.

FROW, Pennie et al. Managing co-creation design: a strategic approach to innovation. British Journal of Managemente, v. 26, n. 3, p. 463-483, jul. 2015.

FULLER, Johann; MATZLER, Kurt. Virtual product experience and customer participation - a chance for customer-centred, really new products. Technovation, v. 27, n. 6, p. 378-387, jun. 2007.

GUSTAFSSON, Anders; KRISTENSSON, Per; WITELL, Lars. Customer co-creation in service innovation: a matter of communication? Journal of Service Management, v. 23, n. 3, p. 311-327, 2012.

HAIR, J.F. et al. Análise multivariada de dados. 5 ed. Porto Alegre: Bookman, 2005.

HAUGLAND, Sven A. Factors influencing the duration of internacional buyer-seller relationships. Journal of Business Research. New York, v. 46, n. 3, p. 273-280, 1999.

HUERTAS, Melby Karina Zuniga; VARELA, Carmen Augusta; STREHLAU, Suzane. Cocriação na internet: uma análise das perspectivas da empresa e do consumidor. Revista de Administração e Inovação, São Paulo, v. 9, n. 3, p. 257-272, jul./set. 2012.

HUMPHREYS, Ashlee; GRAYSON, Kent. The intersecting roles of consumer and producer: a critical perspective on co-production, co-creation and presumption. Sociology Compass, v. 2, p. 963-980, mai. 2008.

LAMPERT, Sérgio Renato; FLORES, Daniel. Os sitemas de workflow em arquivística: a identificação dos modelos e a análise das ferramentas. Perspectiva em Ciência da Informação, Belo Horizonte, v. 15, n. 3, p. 216-232, set./dez. 2010.

MATTING, Jonas; SANDÉN, Bodil; EDVARDSSON, Bo. New service development: learning from and with customers. International Journal of Service Industry Management, v. 15, p. 479498, 2004.

NGO, Liem Viet; O'CASS, Aron. Innovation and business success: the mediating role of customer participation. Journal of Business Research, v. 66, n. 8, p. 1134-1142, ago. 2013.

PAYNE, Adrian F.; STORBACKA, Kaj; FROW, Pennie. Managing the co-creation of value. Journal of the Academy of Marketing Science, v. 36, n. 1, p. 83-96, mar. 2008.

PRAHALAD, C.K.; RAMASWAMY, Venkatram. Co-opting customer competence. Harvard Business Review, v. 78, n. 1, p. 79-88, jan./fev. 2000.

PRAHALAD, C.K.; RAMASWAMY, Venkatram. The co-creation connection. Strategy and Business, v. 27, p. 50-61, 2002.

PRAHALAD, C.K.; RAMASWAMY, Venkatram. Co-creation experiences:the next practice in value creation. Journal of Interactive Marketing, v. 18, n. 3, p. 5-14, $2004 \mathrm{a}$. 
PRAHALAD, C.K.; RAMASWAMY, Venkatram. Co-creating unique value with customers. Strategy \& Leadership, v. 32, n. 3, p. 4-9, 2004b.

PRAHALAD, C.K.; RAMASWAMY, Venkatram. 0 futuro da competição: como desenvolver diferenciais inovadores em parceria com os clientes. Rio de Janeiro, Elsevier, 2004c.

POPPO, Laura; ZENGER, Todd. Do formal contracts and realcional governance function as substitutes or complements? Strategic Management Journal, v. 23, n. 8, p. 707-725, maio 2002.

RAFAELI, Sheizaf; ARIEL, Yaron. Online motivational factors: incentives for participation and contribution in Wikipedia. ResearchGate, p. 243-267, jan. 2008.

RICHARDSON, Roberto Jarry. Pesquisa Social: métodos e técnicas. São Paulo, Atlas, 1999.

ROCHA, Álvaro; VASCONCELOS, José. Os modelos de maturidade na gestão de sistemas de informação. Revista Faculdade de Ciência e Tecnologia, v. 1, p. 93-107, 2004.

ROCHFORD, Linda. Generating and screening new peoducs ideas. Industrial Marketing Management, v. 20, n. 4, p. 287-296, nov. 1991.

SOFTMARE ENGINEERING INSTITUTE. CMMI ® para Desenvolvimento - Versão 1.2. Pittsburgh, 2006.

SIJTSEMA, Petra Bosch; BOSCH, Jan. User involvement throughout the innovation process in high-tech industries. Journal of Product Innovation Management, v. 32, n. 5, p. 793-807, set. 2015.

SILVEIRA, Victor Natanael Schwetter. Os modelos multiestágios de maturidade: um breve relato de sua história, sua difusão e sua aplicação na gestão de pessoas por meio do People Capability Maturity Model (P-CMM). Revista de Administração Contemporânea, Curitiba, v. 13, n. 2, p. 228-246, abr./jun. 2009.

SILVEIRA, Natanael Schwetter; GUIMARÃES, Ludmila de Vasconcelos Machado; ABRAÃO, Helder Emanuel. Os modelos de maturidade e a gestão de pessoas: o modelo P-CMM. In. ENCONTRO DA ANPAD, 31., 2007, Anais eletrônicos ... Rio de Janeiro, 2007.

SUN, Hongyi; YAU, Hon Keung; SUEN, Eric Kwok Ming. The simultaneous impacto f supplier and customer involvement on new product performance. Journal of Technology Management \& Innovation, Santiago, v. 5, n. 4, p. 70-82, 2010.

TABORDA, Marianna. De consumidor a co-produtor: o potencial das redes sociais. Revista ECOpós, v. 10, n. 2, p.197-211, dez. 2007.

TSUKUMO, A. N. et al. A Framework for Incremental Evaluation of Software Product Quality Based on ISO/IEC 9126. In: Fifth International Conference on Software Quality Management, SQM'97, 1997, Bath, UK, p. 111-121, 1997.

VAN HOI, Pham; MOL, Arthur PJ; OOSTERVEER, Peter JM. Market governance for safe food in developing countries: the case of low-pesticide vegetables in Vietnam. Journal of Environmental Management, v. 91, n. 2, p. 380-388, nov./dez. 2009.

VARGO, Stephen L.; MAGLIO, Paul P.; AKAKA, Melissa Archpru. On value and value co-creation: a servisse systems and servisse logic perspective. European Management Journal, v. 26, n. 3, p. 145-152, jun. 2008. 
VON HIPPEL, Eric; KATZ, Ralph. Shifting innovation to users via toolkits. Management Science, v. 48, n. 7, p. 821-833, jul. 2002.

WOODRUFF, Robert B. Customer value: the next source for competitive advantage. Journal of the Academy of Marketing Science, v. 25, n. 1, p. 139-153, 1997.

ZMOGINSKI, Amanda Saraiva et al. Co-criação de valor: inovação no modelo de negócio obtendo vantagem competitiva. Revista Jovens Pesquisadores, v. 6, n. 10, jan./jul. 2009. 